\title{
Tuning the strength of the resonance-assisted hydrogen bond in o-hydroxybenzaldehyde by substitution in the aromatic ring ${ }^{1}$
}

\author{
Gerard Pareras ${ }^{\mathrm{a}}$, Marcin Palusiak ${ }^{\mathrm{b}}$, Miquel Duran ${ }^{\mathrm{a}}$, Miquel Solàa, ${ }^{\mathrm{a},}$, and Sílvia Simon ${ }^{\mathrm{a}, \star}$ \\ (a) Institut de Química Computacional i Catàlisi and Departament de Química, Universitat de \\ Girona, C/ Maria Aurèlia Capmany 69, 17003 Girona, Catalonia, Spain \\ (b) Department of Theoretical and Structural Chemistry, Faculty of Chemistry, University of Łódź, \\ Pomorska 163/165, 90-236 Łódź, Poland
}

\begin{abstract}
Intramolecular resonance-assisted hydrogen bonds (RAHBs) are stronger than conventional hydrogen bonds ( $\mathrm{HBs}$ ) thanks to the extra stabilization connected with the partial delocalization of the $\pi$-electrons within the HB motif containing conjugated formally single and double bonds. When these conjugated bonds are part of an aromatic ring, there is an interplay between resonance-assisted hydrogen bonding and the aromaticity of the ring. The main aim of the present work is to analyze the changes in RAHB strength by substitution in the aromatic ring. For this purpose, we use density functional theory methods to study all possible mono- and di-substitutions in the four free positions of the aromatic ring in o-hydroxybenzaldehyde. As substituents, we consider three $\pi$-electron donating groups (EDG: $\mathrm{NH}_{2}, \mathrm{OH}$, and $\mathrm{F}$ ) and three $\pi$-electron withdrawing groups (EWG: $\mathrm{NO}_{2}, \mathrm{NO}$, and $\mathrm{CN}$ ). We show that it is possible to tune the $\mathrm{HB}$ bond distance in the RAHB by locating different substituents in given positions of the aromatic ring. Indeed, certain combinations of EDG and EWD result in a reduction or increase of the HB distance by up to $0.05 \AA$. Results found can be explained by considering the existence of a resonance effect of the $\pi$-electrons within the HB motif.
\end{abstract}

Keywords: Resonance-assisted hydrogen bonding, local aromaticity, para delocalization index, o-hydroxybenzaldehyde derivatives, quasi-ring.

\footnotetext{
1 This work is dedicated to Profs. Manuel Yáñez and Otilia Mó as a proof of our admiration for their brilliant contributions to chemistry and for having taken care of several generations of Spanish theoretical and computational chemists.
} 


\section{Introduction}

Hydrogen bonds (HBs) are one of the most studied weak inter- or intramolecular interactions. HBs play an important role in many chemical and biological processes. For instance, HBs determine the crystal structure as well as stabilization of second-order structure of proteins. ${ }^{1-3}$ Resonance-assisted hydrogen bonds (RAHB) were introduced by Gilli et al. in $1989^{4}$ as a particular case of $\mathrm{H}$-bonding strengthened by a conjugated $\pi$-system forming a 6-, 8-, or 10 membered ring. ${ }^{5}$ According to Gilli and coworkers, RAHBs are stronger than conventional hydrogen bonds (HBs) because of the extra stabilization gained due to the partial delocalization of the $\pi$-electrons within the HB motif containing conjugated formally single and double bonds. Figure 1 depicts the RAHB in malonaldehyde. The six-membered ring formed by the conjugated formally single and double bonds and the HB is known as the quasi-ring moiety. ${ }^{6}$ Characteristic elongation of formally double bond and shortening of formally single bonds in the quasi-ring together with a strengthening of $\mathrm{HB}$ are fingerprints of RAHBs. ${ }^{7-11}$ The stabilization energy released upon RAHB formation was shown to exhibit good correlation with the electron delocalization indices between the hydrogen and proton-acceptor atoms in $\mathrm{H}$-bridge. ${ }^{12}$ Thus, the electron delocalization induced when a quasi-ring is built is closely related to the strength of this HB.

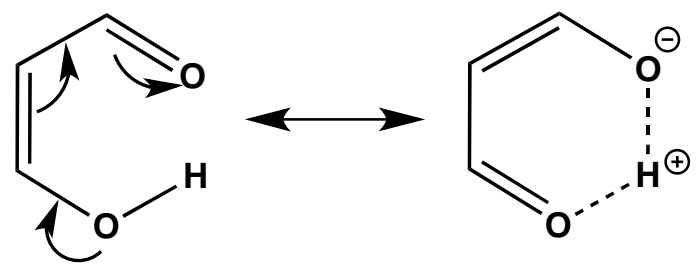

Figure 1. The two main resonance structures involved in the resonance-assisted hydrogen bond in malonaldehyde. 
When these conjugated bonds are part of an aromatic ring, there is an interplay between resonance-assisted hydrogen bonding and aromaticity of the ring as discussed by some of us in a series of $o$-hydroxyarylaldehydes (Figure 2) $)^{12,13}$ and by Houjou et al. ${ }^{14}$ for $\pi$-fused salicylaldehydes. For this kind of systems, one can separate the $\pi$-resonance effect in three different individual effects, ${ }^{13}$ namely, (a) the delocalization within the quasi-ring, identified by Gilli et al. ${ }^{4}$ and already present in malonaldehyde, (b) the effect of the $\pi$-electron delocalized within the benzene ring, and (c) the substituent effect of hydroxyl group (electron-donating group) and carbonyl (electron-withdrawing) that favours the canonical structure with charge separation (structure II in Figure 2). Compared to malonaldehyde, with $\mathrm{C}=\mathrm{C}$ localized double bond, effects (a) and (c) cooperate with each other, so reinforcing the HB, while (b) goes against HB formation. The interplay between intramolecular RAHB and aromaticity (effect (b)) was demonstrated in o-hydroxyarylaldehydes as well as in 1,3-dihydroxyaryl-2-aldehydes by some of us. ${ }^{12,13} \mathrm{We}$ found that both systems present a stabilization of the RAHB depending on the degree of localization of electrons at the $\mathrm{C}_{1}=\mathrm{C}_{2}$ bond shared between both rings, which is related to aromaticity of the benzene ring.

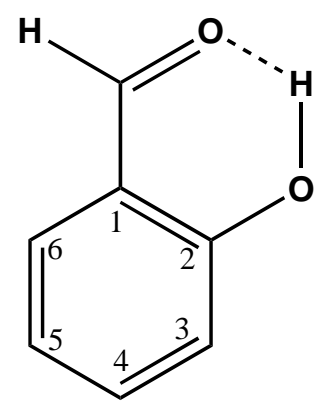

I

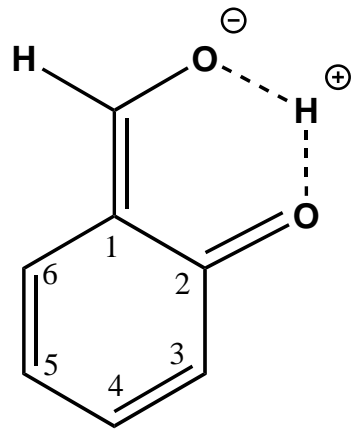

II

Figure 2. The two main resonance structures in o-hydroxybenzaldehyde with the numbering of the benzene ring used to name the different derivatives obtained after substitution.

From previous works by Krygowski and co-workers on the effect of the substituent in hydrogen bonding and aromaticity, ${ }^{15-18}$ one can postulate that substituted o- 
hydroxybenzaldehyde (Figure 2) will present different HB strengths depending on the nature and position of the substituents in the aromatic ring. Two different kind of substituents with opposite electronic character can be considered (defined from their effect on electrophilic aromatic substitutions). ${ }^{19} \mathrm{First}, \pi$-electron donating groups (EDG), known as ortho and para-activating groups, as they increase the electron density of the ring, especially in ortho and para positions. On the other hand, $\pi$-electron withdrawing groups (EWG) decrease the electron density of the ring, especially in ortho and para positions, thus, directing substitution into the meta one. This different electronic behavior can change the proton acceptor and donor properties of the $\mathrm{HCO}$ and $\mathrm{OH}$ groups in o-hydroxybenzaldehyde, reinforcing or weakening the intramolecular $\mathrm{HB}$ (shortening or enlarging its $\mathrm{HB}$ distance). The main goal of this paper is to study the substituent effect on the HB strength of o-hydroxybenzaldehyde. To this end, we will consider all possible mono- and di-substitutions in the four free positions of o-hydroxybenzaldehyde (positions 3 to 6 , Figure 2) considering three $\pi$-electron donating groups (EDG: $\mathrm{NH}_{2}, \mathrm{OH}$, and $\mathrm{F}$ ) and three $\pi$-electron withdrawing groups (EWG: $\mathrm{NO}_{2}, \mathrm{NO}$, and $\mathrm{CN}$ ). As shown in next sections, our results indicate that the HB strength/distance changes significantly depending on the position of the substituents in the aromatic ring.

The original interpretation by Gilli et al. of resonance as the origin of the extra stabilization in RAHB has been recently supported by block-localized wave functions calculation by Mo et al. ${ }^{20,21}$ However, one can find other interpretations of this phenomenon in the literature. For instance, Beck and $\mathrm{Mo}^{22}$ claimed that enhancement of the HB interaction in RAHBs is due to dipole-dipole electrostatic interactions, and not to resonance. Others, like Yáñez, Mó et al., ${ }^{23,24}$ in a landmark study argued that the characteristics of the $\sigma$-skeleton, and not the RAHB phenomenon, are the main responsible for the extra stability of this interaction. Finally, in a recent paper, Guevara-Vela and coworkers ${ }^{25}$ performed a quantum chemical topological study to conclude that there is an increase in electron localization of $\pi$-electrons (not delocalization as expected from Gilli's 
interpretation) in the quasi-ring of RAHB. This localization leads to greater electrostatic, polarization, and charge transfer effects that result in stronger $\mathrm{H}$ bonds. These works show that several interpretations on the role played by $\pi$ electrons in the strengthening of RAHBs exist. In the present work, we will not analyze the nature of the RAHB interaction. However, we anticipate here that our results can be positively explained from the original interpretation of Gilli and coworkers based on resonance effects. ${ }^{4}$

\section{Computational methods}

All molecules considered in this study were optimized at the nonlocal threeparameter hybrid B3LYP level of theory ${ }^{26,27}$ using the $6-311++G(d, p)$ basis set. Vibrational analyses of optimized structures showed that, in general, the structures are minima in the potential energy surface. Some of them exhibit imaginary frequencies due to the planarity imposed to the systems (see Tables S1 and S2 of the supporting information). All calculations were carried out with the Gaussian 09 package. ${ }^{28}$ Electron delocalization indices (DIs) ${ }^{29}$ have been obtained using AIMAII ${ }^{30}$ and ESI-3D ${ }^{31,32}$ programs.

DIs are among the most popular bonding indicators. They provide a quantitative information on the electron density shared between two atoms/fragments $A$ and B. ${ }^{33}$ The DI between atoms $A$ and $B, \delta(A, B)$, is obtained by double integration of the exchange-correlation density, $\Gamma_{x c}\left(\overrightarrow{r_{1}}, \overrightarrow{r_{2}}\right)$, over their respective atomic domains $\Omega_{A}$ and $\Omega_{B}$ as:

$$
\delta(A, B)=-2 \int_{\Omega_{A}} \int_{\Omega_{B}} \Gamma_{X C}\left(\vec{r}_{1}, \vec{r}_{2}\right) d \overrightarrow{r_{1}} d \vec{r}_{2}
$$

In the particular case of a single-determinant closed-shell wavefunction, the DI can be expressed solely in terms of the elements of the atomic overlap matrices $\mathbf{S}(A)$ in the molecular orbital basis according to: 


$$
(A, B)=4{ }_{i, j}^{o c c} S_{i j}(A) S_{j i}(B)
$$

where the summation runs over all doubly-occupied molecular orbitals. In this work, the atomic partition is defined from the condition of zero-flux gradient in the one-electron density following the Quantum Theory of Atoms in Molecules (QTAIM). ${ }^{34}$

Based on the finding of Fulton ${ }^{35}$ and Bader ${ }^{36}$ who showed that benzene has larger DIs in para-related atoms than in meta-related ones, the PDI index ${ }^{37,38}$ uses the DIs of para-related atoms as a measure of aromaticity for six-membered rings:

$$
\operatorname{PDI}(A)=\frac{\left(A_{1}, A_{4}\right)+\left(A_{2}, A_{5}\right)+\left(A_{3}, A_{6}\right)}{3}
$$

For PDI, the larger the index, the greater the aromaticity of the ring. Obviously, this index can only be applied to six-membered rings. We use it to discuss the aromaticity of both the benzene ring (PDI) and the quasi-ring (PDIQ).

It was demonstrated ${ }^{15}$ for simple derivatives of benzene that PDI gives qualitatively the same results as other electronic indices ${ }^{39,40}$ as well as indices like the HOMA structural index ${ }^{41}$ or the NICS magnetic index. ${ }^{42}$ For this reason, in our studies we are using exclusively the PDI index. 


\section{Results and discussion}

This section is organized as follows. First, we analyze monosubstituted ohydroxybenzaldehyde systems with substituents of diverse electronic character in different positions of the aromatic ring. Second, we consider disubstituted 0 hydroxybenzaldehyde with two different substituents to analyze how they cooperate or interfere each other as a function of their electronic character and position. Finally, a general discussion about how resonance assists the HB formation is provided.

\section{A. Monosubstituted o-hydroxybenzaldehyde compounds}

In the present work, we have dealt with three different $\pi$-electron donating groups (EDG) and three $\pi$-electron withdrawing groups (EWG). The groups chosen in this paper present a $\sigma_{\mathrm{R}}$ Hammet constant (resonance effect parameter, R, collected in Table 1) characteristic of their electronic character: negative for $\pi$-electrondonating groups $\left(\mathrm{F}, \mathrm{OH}\right.$, and $\left.\mathrm{NH}_{2}\right)$ and positive for $\pi$-electron-withdrawing ones (NO, $\mathrm{NO}_{2}$, and $\mathrm{CN}$ ). ${ }^{19}$ Throughout this work, we name our compounds with the nomenclature 1,2,N-X, where the first two numbers (1 and 2, Figure 2) refer to the position of the $\mathrm{HCO}$ and $\mathrm{OH}$ groups, whereas the third number $\mathrm{N}(\mathrm{N}=3$ to 6$)$ is related to the position of the substituent (e.g. 1,2,3-NO2 is 2-hydroxy-3nitrobenzaldehyde). Tables S3 and S4 in the ESI list the IUPAC nomenclature for all systems studied.
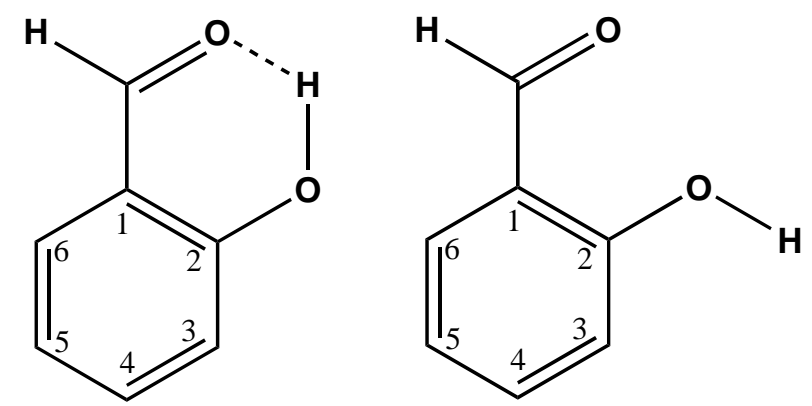

Figure 3. Open and closed conformers for o-hydroxybenzaldehyde. 
Table 2 collects the relative energies with respect to species $1,2,3-X(X=E D G$ or $E W G$ ) isomers, the HB distances and the PDIs for the benzene ring (PDI). It also lists $E_{\text {diff, }}$ which is the energy difference between open and closed conformers (see Figure 3). Positive values means that the closed conformation is more stable then the open one. As it was pointed out before, three different effects influence the formation of the RAHB. The first one, the electron delocalization within the quasiring, will be equal for all systems, as the quasi-ring presents the same proton donor and acceptor in all cases. The second effect is due to electron delocalization within the benzene ring that is, in general, acting against the formation of RAHB, i.e., the higher the electron delocalization, the less available the $\pi$-electrons shared between the two rings are and, consequently, the weaker the RAHB. The third effect, the substituent resonance effect can act in favor or against the RAHB, depending on the position of the substituent. As said before, the proton donor $(\mathrm{OH})$ and acceptor ( $\mathrm{HCO}$ ) groups forming the quasi-ring cooperate strengthening the RAHB, as they are in ortho position to each other. ${ }^{43}$

First, we analyze the relative stability of the different substituted 0 hydroxybenzaldehydes. Results in Table 2 show that 1,2,4-EDG and 1,2,5-EWG are the most stable systems. At the same time, these compounds are the less aromatic, with a lower PDI for the benzene ring as well as for the quasi-ring (see Table $\mathrm{S} 1$ for the latter). It is worth mentioning that there is no correlation between the distance of the RAHB and the relative energy of the isomer, the most stable conformer does not have the shortest HB. As it was expected, all substituted compounds present a decrease of the PDI for the benzene ring with respect to non-substituted one, whereas the HB distance can be larger or shorter.

Previous studies of RAHB in aromatic species showed that the strength of the $\mathrm{H}$ bonding is linearly related to the local aromaticity of the benzene ring, i.e., the lower the aromaticity, the stronger the RAHB. ${ }^{13}$ Thus, taking into account the PDI values of the benzene ring in 1,2,N-X species, one should anticipate that all $\mathrm{HB}$ should be stronger, that is with shorter HB distance. As this is not always the case, one can 
conclude that, for some species, resonance effects of substituents are more important than the loss of local aromaticity of the benzene ring. Figure 4 represents the HB distances with respect to the local aromaticity of the benzene ring, measured with PDI. For a better analysis, it has been separated for different positions of the substituent in the ring: blue for $1,2,3-\mathrm{X}$, red for $1,2,4-\mathrm{X}$, green for 1,2,5-X and black for 1,2,6-X, for both EWG (points) and EDG (crosses).

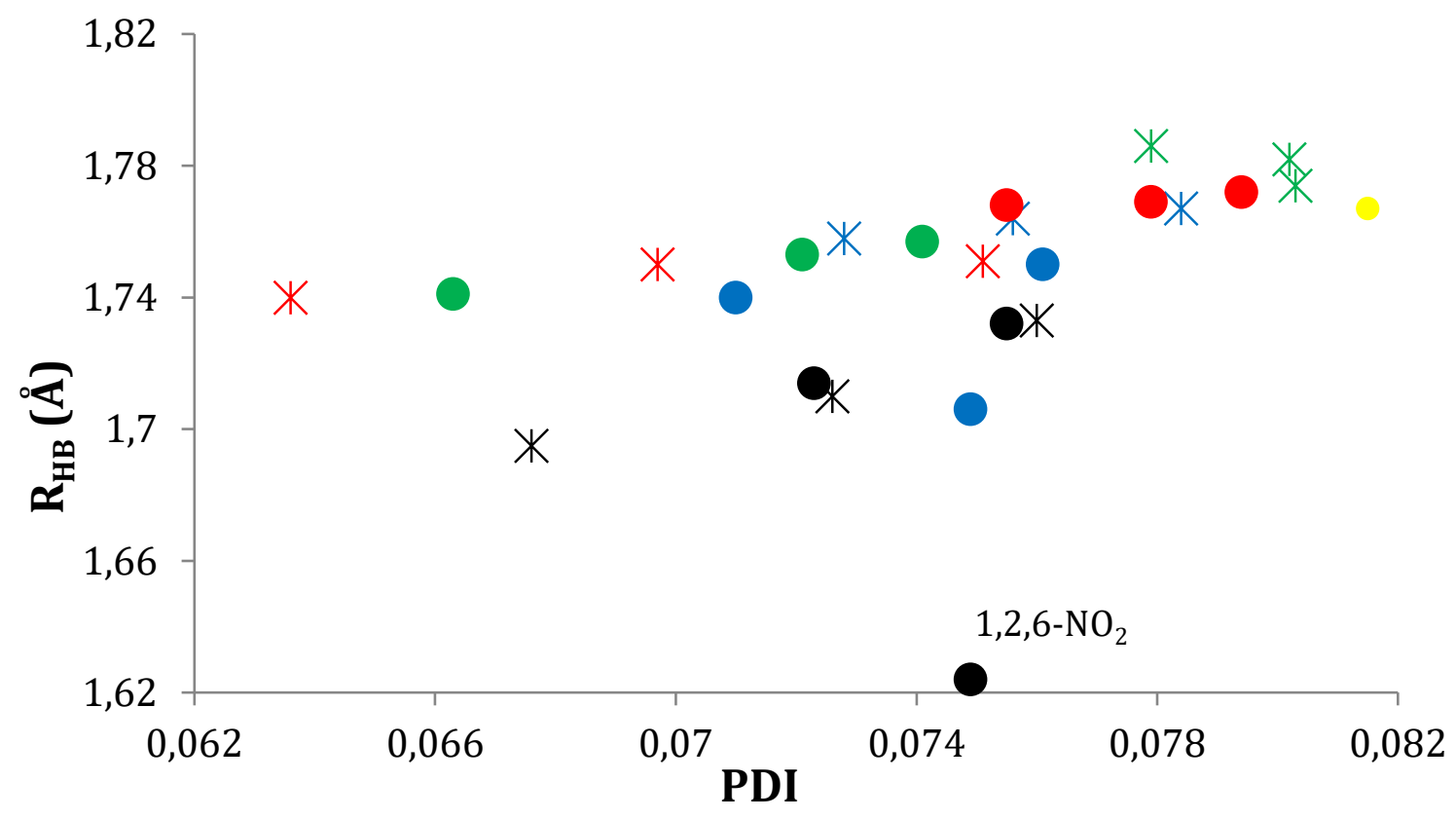

Figure 4. Hydrogen bond distance ( $R_{H B}$ in $\AA$ ) with respect to PDI (in electrons). Blue for 1,2,3-X, red for 1,2,4-X, green for 1,2,5-X and black for 1,2,6-X. Crosses for EDG and points for EWG. Yellow point for unsubstituted o-hydroxybenzaldehyde.

As it was explained before, EDGs bring more electron density especially at ortho and para positions, whereas EWGs reduce it at these positions. To increase the RAHB strength, the $\mathrm{C} 1$ carbon atom (substituted by $\mathrm{HCO}$ group) needs to accumulate electron density by carrying formal negative charge which can be transferred onto the attached HCO group, enhancing in that way its proton acceptor character. Simultaneously the $\mathrm{C} 2$ carbon atom (substituted by $\mathrm{OH}$ ) increase the proton donating ability when carrying formal positive charge. As both substituents forming the RAHB ( $\mathrm{HCO}$ and $\mathrm{OH}$ ) are in ortho position to each other, thus being favorably conjugated in the sense of the $\pi$-electron resonance, these 
two effects (activation of $\mathrm{HCO}$ and deactivation of $\mathrm{OH}$ groups and vice versa) in 0 hydroxybenzaldehyde always act together.

Let us start by analyzing the EWGs, which decrease the electron density throughout the benzene ring, being more noticeable at ortho and para positions. According to the numbering scheme of Figure 2, substituents in positions 3 and 5 are in ortho and para positions with respect to the $\mathrm{OH}$ group. Consequently, we expect an increase in its proton donor character, so strengthening and shortening the HB distance. As can be seen in Table 2, 1,2,3-EWG and 1,2,5-EWG species present shorter HB distance compare to non-substituted $o$-hydroxybenzaldehydes (e.g. $1.750 \AA$ for $1,2,3-\mathrm{CN}$ and $1.741 \AA$ for $1,2,5-\mathrm{NO}$ to be compared to $1.767 \AA$ for the unsubstituted 1,2- $\mathrm{H}$ species). The original interpretation of Gilli and coworkers ${ }^{4}$ of the RAHB together with the resonance structures represented in Figure 5 provide an explanation for the activation of the RAHB by EWGs attached to $\mathrm{C} 3$ or $\mathrm{C} 5$, showing a decrease in the electron density of the $\mathrm{C} 2$, bonded to $\mathrm{OH}$. On the other hand, following the same line of reasoning, 1,2,4-EWG and 1,2,6EWG systems should present larger HB lengths due to an electron density reduction in $\mathrm{C} 1$ (see Figure $\mathrm{S} 1$ in the $\mathrm{SI}$ ). This is exactly what happens for 1,2,4EWG compounds (red points in Figure 4). On the other hand, 1,2,6-EWG (green points) compounds do not follow the expected trend. We will come back to this exception later on.
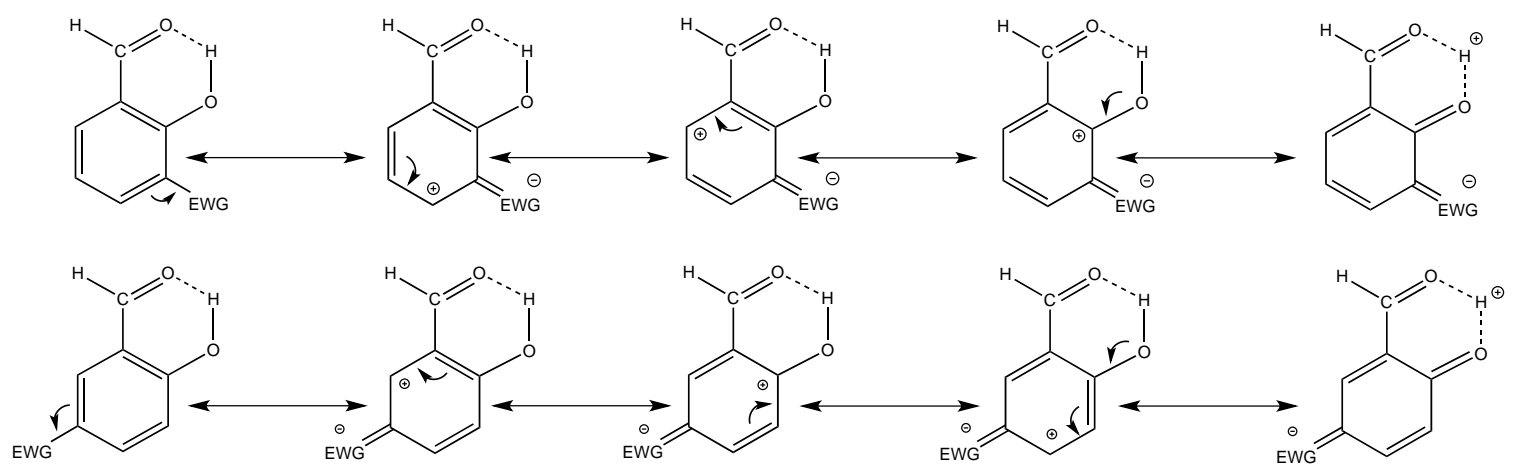

Figure 5. Resonance structures for o-hydroxybenzaldehydes substituted in C3 and C5 by EWGs. 
EDGs are known to activate ortho and para positions, increasing their electron density, as can be observed in Figure 6, where different resonance structures are represented. In that case, 1,2,4-EDG and 1,2,6-EDG are predicted to have shorter HB distances when compared to the non-substituted compounds. For instance, 1,2,4- $\mathrm{NH}_{2}$ and 1,2,6- $\mathrm{NH}_{2}$ species present shorter HB distances (1.740 $\AA$ and 1.695 $\AA$ respectively) in comparison with o-hydroxylbenzaldehyde (1.767 $\AA$ ). On the contrary, 1,2,3-EDG and 1,2,5-EDG are expected to reduce the proton donating ability of hydroxyl group (resonance structure with formal negative charge in C2 atom), weakening the RAHBs, and increasing the HB distances. This behavior is found in 1,2,5-EDG compounds. But similar to 1,2,6-EWG species, 1,2,3-EDG compounds present some irregular behavior, as they are expected to be deactivating the RAHB but, for $\mathrm{X}=\mathrm{NH}_{2}$, the $\mathrm{HB}$ distance is shortened, whereas for $\mathrm{X}=\mathrm{F}$ and $\mathrm{OH}$ the $\mathrm{HB}$ distance remains more or less unchanged.

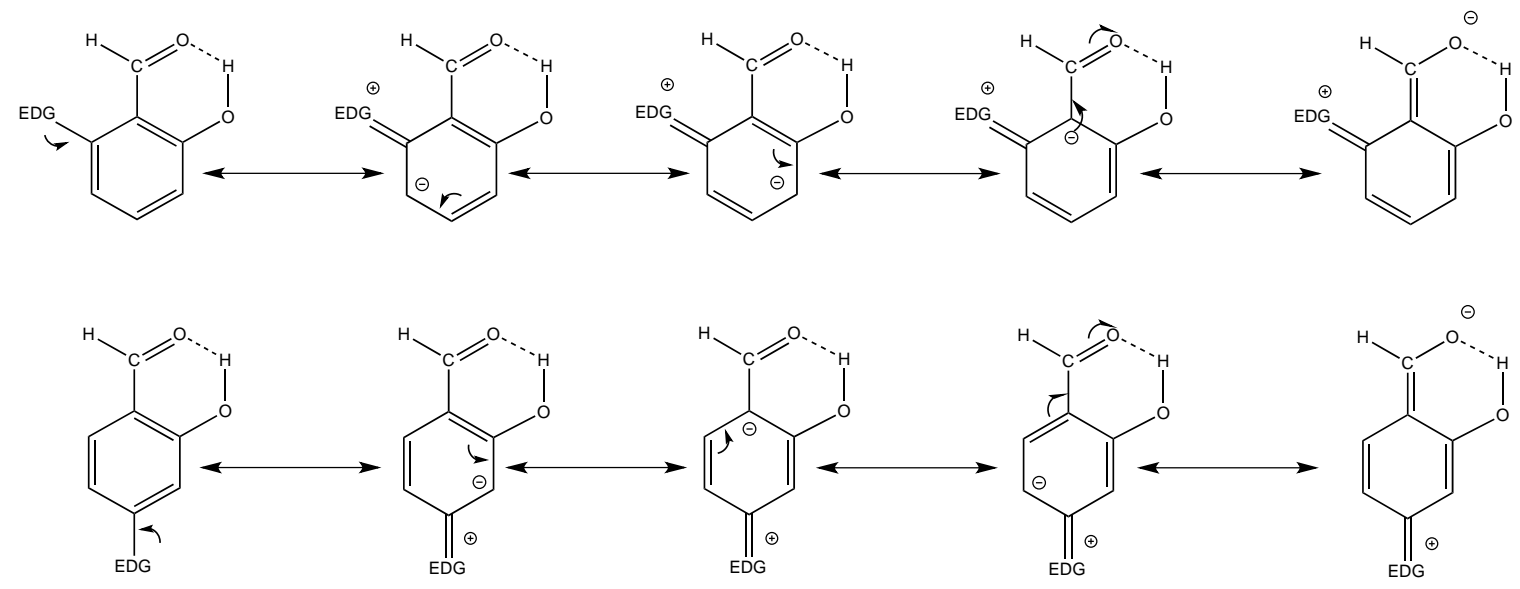

Figure 6. Resonance structures for o-hydroxybenzaldehydes substituted in C4 and C6 for EDG (ortho and para activation).

The 1,2,3- $\mathrm{NH}_{2}$ and 1,2,6-EWG compounds do not behave as expected, presenting shorter HB distances compared to the reference system. The EWG in 1,2,6-EWG species is in ortho position with respect to $\mathrm{CHO}$, so it is likely that steric repulsions between the EWG and the $\mathrm{CHO}$ substituent induces a closure of the quasi-ring leading to shorter HB distances. This effect can be assessed with the angle formed by $\mathrm{C}-\mathrm{C} 1-\mathrm{C} 2$ atoms in the quasi-ring. The average of the former angle in the rest of 
compound is about $120.5^{\circ}$, while in $1,2,6-\mathrm{NO}_{2}$ decreases to $117.3^{\circ}$ (see Table S1). This fact confirms that steric effects are playing an important role in 1,2,6-X systems that are the compounds that present the shortest HB distances. All geometrical parameters (angles of the quasi-ring) for all studied systems can be found in the Tables S1 and S2 of the ESI. For EWG substituents in ortho position with respect to $\mathrm{CHO}$, hydrogen bond distance is reduced, but because of steric effect and not by resonance since there is no resonance structure reinforcing the RAHB.

For 1,2,3- $\mathrm{NH}_{2}$ species, as the substituent is in ortho position with respect to $\mathrm{OH}$ one could expect a similar conclusion, i.e., shorter RAHB because of the repulsive effect between $\mathrm{NH}_{2}$ and $\mathrm{OH}$ groups. But examining the O-C2-C1 angle, we find that this angle is larger in $1,2,3-\mathrm{NH}_{2}$ than in the non-substituted ohydroxybenzaldehyde. Therefore, steric effects seem not to be responsible for the shortening of the RAHB. In this particular case, a $\mathrm{H}$-bond between one of the $\mathrm{H}$ atoms of the $\mathrm{NH}_{2}$ substituent and the $\mathrm{O}$ atom of the $\mathrm{OH}$ group is formed. Formation of this $\mathrm{HB}$, results in some charge transfer from the $\mathrm{OH}$ group to the $\mathrm{NH}_{2}$ substituent and, consequently, a reinforcement of the RAHB. This situation is not different from other observed cases of hydrogen-bonding cooperativity. ${ }^{44,45}$

Going back to the three different effects discussed above, not only the substituent effect plays a role, but also the aromaticity of the benzene ring. A decrease of the PDI, that is, $\pi$-electrons being more localized, can shorten or enlarge the HB distance. It depends whether $\pi$-electron density is more localized in the C1-C2 bond or in the $\mathrm{C} 1-\mathrm{C} 6$ bond. Localization in the $\mathrm{C} 1-\mathrm{C} 2$ bond strengthens the RAHB. This is not generally the main effect and it is masked by the substituent activation of proton donor and acceptor character of $\mathrm{HCO}$ and $\mathrm{OH}$. As reported by Krygowski et al., ${ }^{15}$ we also find that $\mathrm{NH}_{2}$ and $\mathrm{NO}$ are the substituents that bring a largest decrease in the aromaticity of the benzene ring (see Table 1). Indeed, 1,2,3-NO and 1,2,6- $\mathrm{NH}_{2}$ have a PDI of 0.071 e and $0.068 \mathrm{e}$, respectively, when they are in activating positions, but also they show similar decrease when they are in non- 
activating position (PDI of 0.073 e for $1,2,3-\mathrm{NH}_{2}$ and of 0.072 e for $1,2,6-\mathrm{NO}$ to be compared with 0.082 for the unsubstituted system). This important decrease is followed by a localization of density in C1-C2 bond, DI being 1.264 e for 1,2,3- $\mathrm{NH}_{2}$ and $1.242 \mathrm{e}$ for $1,2,6-\mathrm{NO}$, much larger than $1.225 \mathrm{e}$ for the unsubstituted $1,2-\mathrm{H}$ species (see Table S1). For 1,2,3- $\mathrm{NH}_{2}$ and 1,2,6-NO species, the decrease of aromaticity of the benzene ring strengthens the RAHB by localizing $\pi$-electron density in the $\mathrm{C} 1-\mathrm{C} 2$ bond, whereas the substituent effect weakens it. The result of these two counteracting effects is a stronger RAHB as compared to the unsubstituted reference.

It is worth noting that, according to Dls, activation groups like 1,2,3-EWG, 1,2,4EDG, 1,2,5-EWG, and 1,2,6-EDG reduce the $\pi$-electron density in the C1-C2 bond as compared to the reference system, whereas the opposite is true for the deactivating groups. It is likely that the reduction of the $\pi$-electron density in the C1-C2 bond by activating groups is in part due to the involvement of the C1-C2 $\pi$ electron density in the strengthening of the RAHB.

Finally, as expected, activating groups have larger $E_{\text {diff }}$ values than their nonactivating counterparts do. For instance, Ediff value is greater in 1,2,4-EDGs than in 1,2,4-EWGs. The only exception corresponds to the 1,2,3-EWGs that have lower $E_{\text {diff }}$ values than the 1,2,3-EDGs, the reason being the formation of an additional $\mathrm{HB}$ between the $\mathrm{OH}$ group and the $\mathrm{X}$ groups in the open conformation. Moreover, the large value of $E_{\text {diff }}$ in $1,2,3-\mathrm{NH}_{2}$ species is due to the $\mathrm{H} \cdots \mathrm{H}$ steric repulsion present in the open conformation (see Figure 8b).

To sum up, in monosubstituted o-hydroxybenzaldehydes, EWG and EDG activate (shortening) or deactivate (enlarging) the intramolecular HB. The activation is clearly found in 1,2,4-EDG and 1,2,5-EWG, whereas the deactivation is evident in 1,2,4-EWG and 1,2,5-EDG. For 1,2,4-X and 1,2,5-X, the activating or deactivating character of the substituent is the most important effect, while for 1,2,6-X and 
1,2,3-X other effects such as steric repulsions, additional HB formation, and $\pi$ electron localization in the $\mathrm{C} 1-\mathrm{C} 2$ bond may help the RAHB formation.

\section{B. Disubstituted o-hydroxybenzaldehydes}

Once we got a picture of the effect that the different substituents have on the RAHB of monosubstituted o-hydroxybenzaldehydes, it will be interesting to take a look at the possible cooperativity between two substituents in disubstituted ohydroxybenzaldehydes. So, we combined one EWG and one EDG with the same activating or deactivating character, based on the conclusions we found for monosubstituted compounds. These compounds are named by adding the second substituent with the number of its position in the benzene ring (Figure 2) (eg. 1,2,3$\mathrm{NH}_{2}-6-\mathrm{NO}_{2}$ is the 3-amino-2-hydroxy-6-nitrobenzaldehyde with $\mathrm{NH}_{2}$ in ortho position with respect $\mathrm{OH}$ and $\mathrm{NO}_{2}$ in ortho position with respect $\mathrm{HCO}$ ). Four different combinations were taken into account: the addition of activating groups 1,2,3-EWG-6-EDG and 1,2,4-EDG-5-EWG and the deactivating ones 1,2,3-EDG6-EWG and 1,2,4-EWG-5-EDG. Comparing the stability between the four sets of compounds, the trend is the same found for monosubstituted species, the 1,2,4EDG-5-EWG compounds being the most stable and having the largest Ediff values with exception of the 1,2,3- $\mathrm{NH}_{2}-6-\mathrm{X}$ species that have the already mentioned $\mathrm{H} \cdots \mathrm{H}$ repulsion in the open conformation (see Table 3 and Figure 8b). These disubstituted systems also are the less aromatic ones, presenting lower PDI for both the benzene ring and the quasi-ring (see Table S2). There is also no direct relation between $\mathrm{HB}$ distances and HB strength measured by $E_{\text {diff }}$ values.

As it was demonstrated above, 1,2,3-X and 1,2,6-X present two or more effects that do not necessarily work in the same direction. On the other side, 1,2,4-X and $1,2,5-\mathrm{X}$ were following a clear pattern, related to the activating or deactivating character of substituent, so we will focus the next discussion in 1,2,4-X-5-Y systems. All data related to the rest of disubstituted systems are collected in Table 3 (together with Table S2 and Figure S3 in the supporting information). Figure 7 represents the PDI of the benzene ring in front of HB distance for 1,2,4-EWG-5- 
EDG (points) and 1,2,4-EDG-5-EWG (crosses). The same representation including the 1,2,3-X-6-Y compounds is found in Figure S3 of the supporting information.

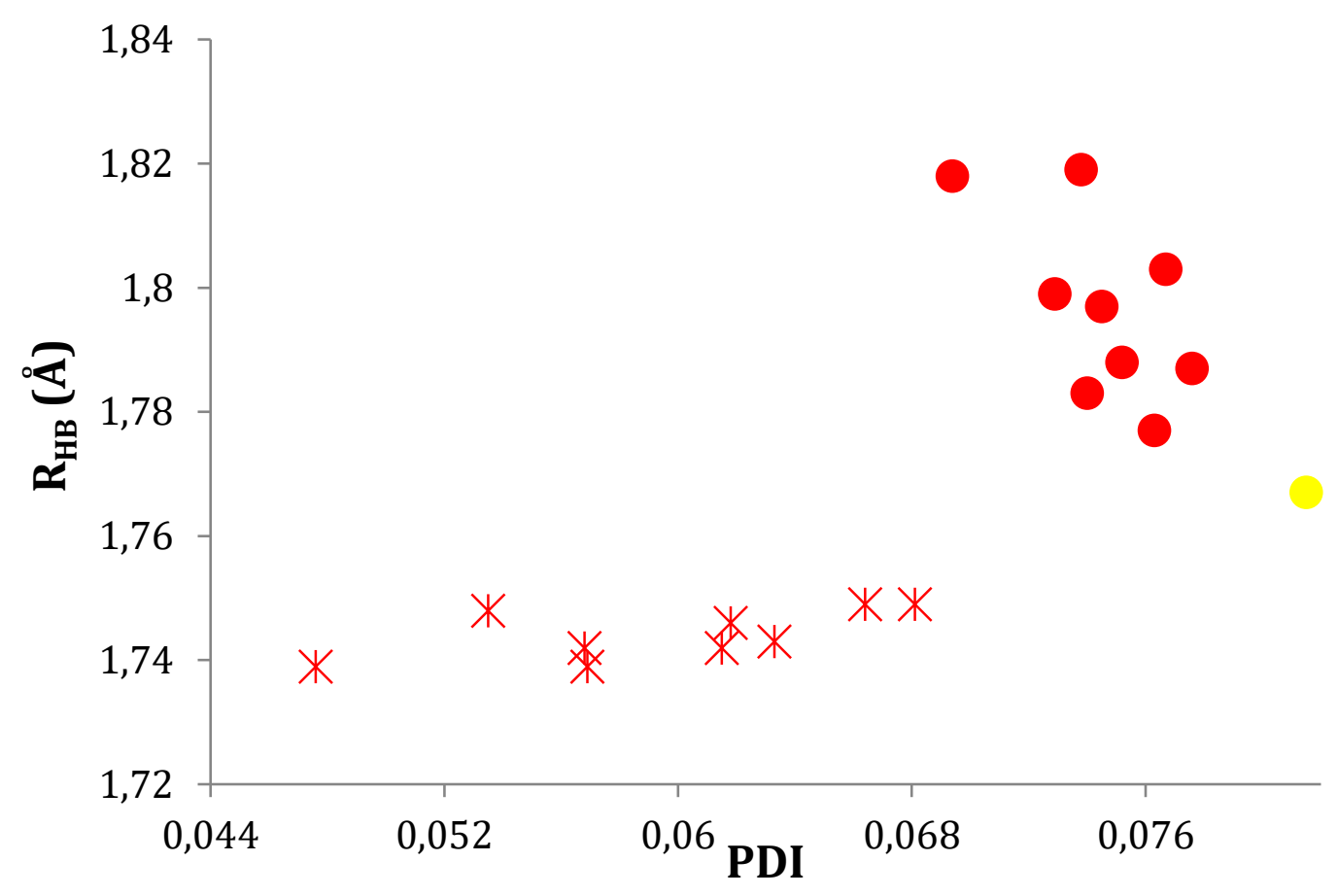

Figure 7. Aromaticity of the benzene ring (PDI, in $\mathrm{e}^{-}$) with respect to HB distance (in $\AA$ ) for disubstituted 1,2,4-X-5-Y compounds. Points for 1,2,4-EWG-5-EDG species and crosses for 1,2,4-EDG-5-EWG compounds. In yellow, the unsubstituted 1,2-H reference system.

From previous discussion, one would expect that 1,2,4-EDG-5-EWG will help to the activation of RAHB, shortening the HB. This is what is observed in Table 3 and Figure 7 (red crosses), where all these disubstituted o-hydroxybenzaldehydes present similar HB distance, always shorter than the unsubstituted system (in the range 1.739-1.749 $\AA$ as compared to $1.767 \AA$ for o-hydroxybenzaldehyde). In general, shorter RAHBs are connected with a larger contribution of the $\pi$-electron density to the formation of the RAHB and, consequently, a reduction of the aromaticity of the benzene ring. At the same time, because their deactivating character, 1,2,4-EWG-5-EDG have larger HB bond lengths, up to $1.819 \AA$ for 1,2,4$\mathrm{NO}_{2}-5-\mathrm{NH}_{2}$ but similar aromatic character according to $\mathrm{PDI}$ values. This is because 
contribution of the $\pi$-electron density to the RAHB in 1,2,4-EWG-5-EDG species remains similar to that of the unsubstituted system.

Going a little further, it would be interesting to find out if there is some cooperativity or additivity between the two substituent effects with respect to the resonance assistance of the HB. In Table S2, we list the expected HB distances that results from adding the effects in the HB distance of the two substituents found in the monosubstituted o-hydroxybenzaldehydes. Clearly, in 1,2,4-X-5-Y species, the expected HB distance is always larger than the calculated one, so effects can not be considered additive, but cooperative. For instance, let us consider the 1,2,4$\mathrm{NH}_{2}-5-\mathrm{NO}_{2}$ species, with a HB distance of $1.748 \AA$. By adding the shortening caused by both substituents separately in $1,2,4-\mathrm{NH}_{2}$ and $1,2,5-\mathrm{NO}_{2}$, we could predict a bond length of $1.714 \AA$ that is shorter than the actual HB distance in 1,2,4$\mathrm{NH}_{2}-5-\mathrm{NO}_{2}(1.748 \AA)$. This is not totally unexpected as whereas the $\mathrm{NH}_{2}$ substituent in C4 increases the $\pi$-electron density (mainly in C1 but also in C2), the $\mathrm{NO}_{2}$ group in $\mathrm{C} 5$ removes it (mainly in $\mathrm{C} 2$ but also in $\mathrm{C} 1$ ). The combined effects of the two substituents counteract and, as a result, the two substituents together cannot move the same electron density as the sum of the two separate substituents and, consequently, the effect is not additive.

\section{Resonance assistance in the hydrogen bond formation.}

From the three different effects that are found in the RAHB of substituted ohydroxybenzaldehyde, i.e, resonance within the quasi-ring, aromaticity of the main ring, and substituent effect, we have shown that the two latter rule the changes in the RAHB strength when going from o-hydroxybenzaldenyde to its mono and disubstituted derivatives, cooperating or competing to each other. At this point we would like to answer the question: how the changes in the electron delocalization within the benzene ring affect the HB strength? 
We will proceed by first analyzing the energy associated to the intramolecular RAHB. This energy can be evaluated in an approximated way as the difference between the open and the closed conformers of a given system. These energies (Ediff) are collected in Table 2 for monosubstituted compounds and in Table 3 for disubstituted o-hydroxybenzaldehydes. For 1,2,3- $\mathrm{NO}_{2}$ compound with $\mathrm{NO}_{2}$ group in ortho position with respect to $\mathrm{OH}$, the open conformer presents an extra stabilization because of $\mathrm{HB}$ formation between $\mathrm{OH}$ and $\mathrm{NO}_{2}$ (Figure 8(a)) leading to small $E_{\text {diff, whereas }} 1,2,3-\mathrm{NH}_{2}$ has a higher energy $\left(17.02 \mathrm{kcal} \mathrm{mol}^{-1}\right)$ because of $\mathrm{H} \cdots \mathrm{H}$ repulsion between $\mathrm{OH}$ and $\mathrm{NH}_{2}$ substituents (Figure $8(b)$ ). As for these compounds $E_{\text {diff }}$ is not a good estimate of HB strength, they are excluded from this part of the discussion.

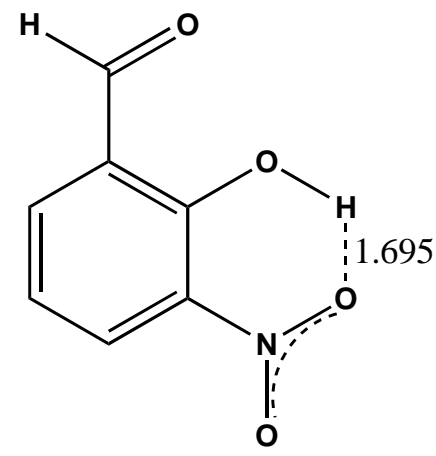

$8(a)$

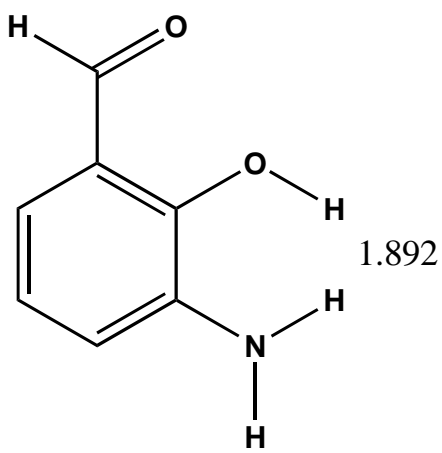

$8(b)$

Figure 8. (a) $1,2,3-\mathrm{NO}_{2}$ and (b) $1,2,3-\mathrm{NH}_{2}$. HB distances in $\AA$.

Our main goal is to assess the relation between the aromaticity of the central ring and the strength of the RAHB. For this purpose, we analyze the change in the aromaticity on benzene ring when going from open to closed conformers. In Figure 9, one can find the change in the PDI (\% $\%$ PDI, difference between PDI of open and closed conformers with respect to the closed one given in percent) plotted against $E_{\text {diff. }}$ As it was found earlier and commented above, it can be seen that there is a direct relation between both parameters: the larger the change in the local aromaticity within the benzene ring, the stronger the HB. This result is also supported by Fig. 9b, where the HB distance $\left(R_{H B}\right)$ is represented, showing a decrease of HB distance with the increase in aromaticity change. Only some 
compounds do not follow the linear correlation, but they correspond to the ones with substituents in ortho positions with respect to $\mathrm{HCO}$ group with repulsive interactions and/or additional HB formation that cause the RAHB to be shorter than expected from the substituent effect.

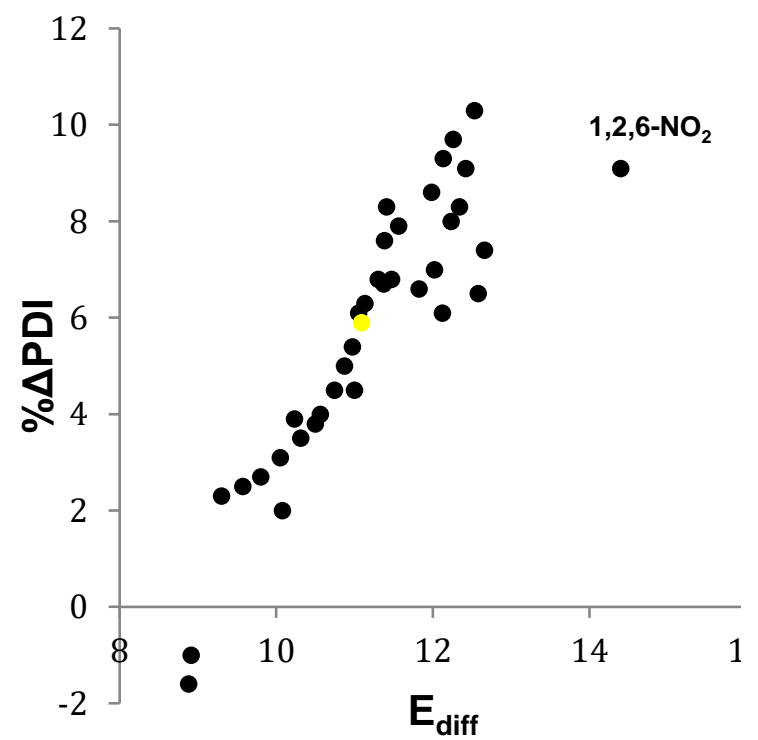

9(a)

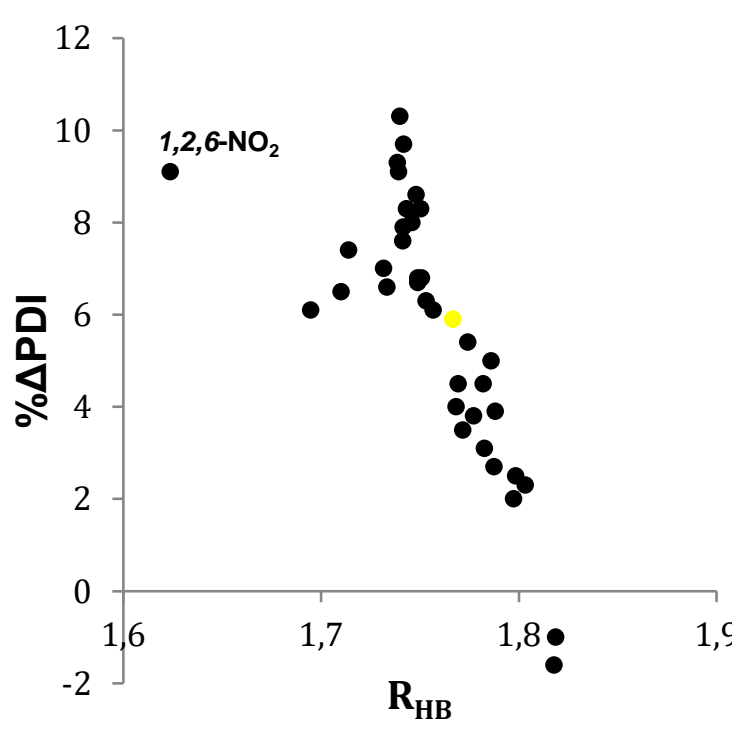

9 (b)

Figure 9. \% $\triangle \mathrm{PDI}$ for the main ring of mono and disubstituted o-hydroxybenzaldehydes in front of (a) energy difference between closed and open conformers $\left(E_{\text {diff, }} \mathrm{kcal} / \mathrm{mol}\right)$ and (b) HB distance (R in $\AA$ ). The yellow dot corresponds to the unsubstituted reference species. Positive values of $\% \triangle \mathrm{PDI}$ means that the aromaticity decrease when going from open to closed conformers.

As we have already mentioned, the resonance proceeding within the quasi-ring compete with the effect of the $\pi$-electron delocalization within the substituted benzene ring. In a previous study, ${ }^{12}$ it was found a linear relation between the change of the aromaticity of the main ring with respect to the quasi-aromaticity of the quasi-ring. In our study this relation is not fulfilled, as the third effect (substituent effect) now plays also an important role. The different substituents at different positions add another variable that has to be taken into account. Nevertheless, the change in the aromaticity in the main ring (loss when going from open to closed) 
has a relatively good correlation with RAHB strength, validating the concept of resonance assisted hydrogen bond of Gilli et al. ${ }^{4}$

\section{Conclusions}

Substituted o-hydroxybenzaldehydes have been studied to analyze the strengthening (activation) o weakening (deactivation) of the RAHB. Two main effects can compete with each other: the substituent effect and the change of the aromaticity in the benzene ring. As the substituent effect is concerned, EDGs activate the ortho and para position increasing the strength of the HB for 1,2,4EDG and 1,2,6-EDG, whereas, electron withdrawing substituents in these positions deactivate the formation of the RAHB. On the other hand, these substituents in 1,2,3-EWG and 1,2,5-EWG compounds favor the RAHB formation. Double substitution in $\mathrm{C} 4$ and $\mathrm{C} 5$ atoms of the benzene ring results in cooperative (but not additive) activation or deactivation of the RAHB. Despite there is not a direct relation between aromaticity and RAHB strength for the substituted 0 hydroxybenzaldehydes, the relationship between the change of the aromaticity (\%PDI) of the benzene ring with respect to the strength of the RAHB supports the assistance of the resonance in the hydrogen bond formation.

\section{Acknowledgements}

We are grateful for financial support from the Spanish MINECO (CTQ2017-85341P), the Catalan DIUE (2014SGR931, XRQTC, and ICREA Academia 2014 Award to M.S.), and the FEDER fund (UNGl10-4E-801). MP acknowledges financial Grant OPUS9 2015/17/B/ST4/04050 from National Science Centre, Poland.

\section{Supporting Information}

Tables for energetic, topologic and structural parameters for monosubstituted and di-substituted o-hydroxybenzaldehydes, IUPAC name list, resonance structures for monosubstituted compounds, representation of the benzene ring 
PDI versus HB distances for $1,2,3-X-6-Y$ species and $x y z$ coordinates for all compounds. See DOI: 10.1039/x0xx00000x

\section{References}

(1) Grabowski, S. J. Hydrogen Bonding - New Insights; Springer: The Netherlands, 2006; Vol. 3.

(2) Jeffrey, G. A. An Introduction to Hydrogen Bonding; Oxford University Press: USA, 1997.

(3) Molecular Interactions: From Van Der Waals to Strongly Bound Complexes; Scheiner, S., Ed.; Wiley \& Sons: UK, 1997.

(4) Gilli, G.; Bellucci, F.; Ferretti, V.; Bertolasi, V. Evidence for Resonance-Assisted Hydrogen Bonding from Crystal-Structure Correlations on the Enol Form of The $\beta$-Diketone Fragment. J. Am. Chem. Soc. 1989, 111, 10231028.

(5) Mahmudov, K. T.; Pombeiro, A. J. L. Resonance-Assisted Hydrogen Bonding as a Driving Force in Synthesis and a Synthon in the Design of Materials. Chem. Eur. J. 2016, 22, 16356-16398.

(6) Krygowski, T. M.; Bankiewicz, B.; Czarnocki, Z.; Palusiak, M. QuasiAromaticity—What Does It Mean? Tetrahedron 2015, 71, 4895-4908.

(7) Bertolasi, V.; Ferretti, V.; Gilli, P.; Yao, X.; Lib, C.-J. Substituent Effects on Keto-Enol Tautomerization of $\beta$-Diketones from X-Ray Structural Data and DFT Calculations. New J. Chem. 2008, 32, 694-704.

(8) Kurczab, R.; Mitoraj, M. P.; Michalak, A.; Ziegler, T. Theoretical Analysis of the Resonance Assisted Hydrogen Bond Based on the Combined Extended Transition State Method and Natural Orbitals for Chemical Valence Scheme. J. Phys. Chem. A 2010, 114, 8581-8590.

(9) Paul, B. K.; Guchhait, N. Geometrical Criteria Versus Quantum Chemical Criteria for Assessment of Intramolecular Hydrogen Bond (IMHB) Interaction: A Computational Comparison into the Effect of Chlorine Substitution 
on IMHB of Salicylic Acid in Its Lowest Energy Ground State Conformer. Chem. Phys. 2013, 412, 58-67.

(10) Sobczyk, L.; Grabowski, S. J.; Krygowski, T. M. Interrelation between H-Bond and Pi-Electron Delocalization. Chem. Rev. 2005, 105, 3513-3560.

(11) Woodford, J. N. Density Functional Theory and Atoms-in-Molecules Investigation of Intramolecular Hydrogen Bonding in Derivatives of Malonaldehyde and Implications for Resonance-Assisted Hydrogen Bonding. J. Phys. Chem. A 2007, 111, 8519-8530.

(12) Palusiak, M.; Simon, S.; Solà, M. Interplay between Intramolecular Resonance-Assisted Hydrogen Bonding and Aromaticity in O-Hydroxyaryl Aldehydes. J. Org. Chem. 2006, 71, 5241-5248.

(13) Palusiak, M.; Simon, S.; Solà, M. Interplay between Intramolecular Resonance-Assisted Hydrogen Bonding and Local Aromaticity. II. 1,3Dihydroxyaryl-2-Aldehydes. J. Org. Chem. 2009, 74, 2059-2066.

(14) Houjou, H.; Shingai, H.; Yagi, K.; Yoshikawa, I.; Araki, K. Mutual Interference between Intramolecular Proton Transfer Sites through the Adjoining $\pi$-Conjugated System in Schiff Bases of Double-Headed, Fused Salicylaldehydes. J. Org. Chem. 2013, 78, 9021-9031.

(15) Krygowski, T. M.; Ejsmont, K.; Stepień, B. T.; Cyrański, M. K.; Poater, J.; Solà, M. Relation between the Substituent Effect and Aromaticity. J. Org. Chem. 2004, 69, 6634-6640.

(16) Krygowski, T. M.; Stępień, B. T. Sigma- and Pi-Electron Delocalization: Focus on Substituent Effects. Chem. Rev. 2005, 105, 3482-3512.

(17) Krygowski, T. M.; Zachara-Horeglad, J. E.; Palusiak, M. H-BondingAssisted Substituent Effect. J. Org. Chem. 2010, 75, 4944-4949.

(18) Stasyuk, O. A.; Szatyłowicz, H.; Krygowski, T. M. Effect of the HBonding on Aromaticity of Purine Tautomers. J. Org. Chem. 2012, 77, 4035-4045.

(19) Hansch, C.; Leo, A.; Taft, R. W. A Survey of Hammett Substituent Constants and Resonance and Field Parameters. Chem. Rev. 1991, 91, 165-195. 
(20) Jiang, X.; Zhang, H.; Wu, W.; Mo, Y. A Critical Check for the Role of Resonance in Intramolecular Hydrogen Bonding. Chem. Eur. J. 2017, 23, 1688516891.

(21) Lin, X.; Zhang, H.; Jiang, X.; Wu, W.; Mo, Y. The Origin of the NonAdditivity in Resonance-Assisted Hydrogen Bond Systems. J. Phys. Chem. A 2017, 121, 8535-8541.

(22) Beck, J. F.; Mo, Y. How Resonance Assists Hydrogen Bonding Interactions: An Energy Decomposition Analysis. J. Comput. Chem. 2007, 28, 455466.

(23) Sanz, P.; Mó, O.; Yáñez, M.; Elguero, J. Non-Resonance-Assisted Hydrogen Bonding in Hydroxymethylene and Aminomethylene Cyclobutanones and Cyclobutenones and Their Nitrogen Counterparts. ChemPhysChem 2007, 8, 1950-1958.

(24) Sanz, P.; Yáñez, M.; Mó, O. Resonance-Assisted Intramolecular Chalcogen-Chalcogen Interactions? Chem. Eur. J. 2003, 9, 4548-4555.

(25) Guevara-Vela, J. M.; Romero-Montalvo, E.; Costales, A.; Pendas, A. M.; Rocha-Rinza, T. The Nature of Resonance-Assisted Hydrogen Bonds: A Quantum Chemical Topology Perspective. Phys. Chem. Chem. Phys. 2016.

(26) Becke, A. D. Density - Functional Thermochemistry. III. The Role of Exact Exchange. J. Chem. Phys. 1993, 98, 5648-5652.

(27) Lee, C.; Yang, W.; Parr, R. G. Development of the Colle-Salvetti Correlation-Energy Formula into a Functional of the Electron Density. Physical Review B 1988, 37, 785-789.

(28) Gaussian 09, Revision A.02, Frisch, M. J.; Trucks, G. W.; Schlegel, H. B.; Scuseria, G. E.; Robb, M. A.; Cheeseman, J. R.; Scalmani, G.; Barone, V.; Mennucci, B.; Petersson, G. A.; Nakatsuji, H.; Caricato, M.; Li, X.; Hratchian, H. P.; Izmaylov, A. F.; Bloino, J.; Zheng, G.; Sonnenberg, J. L.; Hada, M.; Ehara, M.; Toyota, K.; Fukuda, R.; Hasegawa, J.; Ishida, M.; Nakajima, T.; Honda, Y.; Kitao, O.; Nakai, H.; Vreven, T.; Montgomery, Jr., J. A.; Peralta, J. E.; Ogliaro, F.; Bearpark, M.; Heyd, J. J.; Brothers, E.; Kudin, K. N.; Staroverov, V. N.; Kobayashi, R.; Normand, J.; Raghavachari, K.; Rendell, A.; Burant, J. C.; lyengar, S. S.; 
Tomasi, J.; Cossi, M.; Rega, N.; Millam, J. M.; Klene, M.; Knox, J. E.; Cross, J. B.; Bakken, V.; Adamo, C.; Jaramillo, J.; Gomperts, R.; Stratmann, R. E.; Yazyev, O.; Austin, A. J.; Cammi, R.; Pomelli, C.; Ochterski, J. W.; Martin, R. L.; Morokuma, K.; Zakrzewski, V. G.; Voth, G. A.; Salvador, P.; Dannenberg, J. J.; Dapprich, S.; Daniels, A. D.; Farkas, Ö.; Foresman, J. B.; Ortiz, J. V.; Cioslowski, J.; Fox, D. J. Gaussian, Inc., Wallingford CT, 2009.

(29) Fradera, X.; Austen, M. A.; Bader, R. F. W. The Lewis Model and Beyond. J. Phys. Chem. A 1999, 103, 304-314.

(30) AIMAll (Version 17.11.14), Todd A. Keith, TK Gristmill Software, Overland Park KS, USA, 2017 (aim.tkgristmill.com)

(31) Matito, E. ESI-3d: Electron Sharing Indices Program for 3d Molecular Space Partitioning; Institute of Computational Chemistry and Catalysis, University of Girona, Catalonia, Spain, 2006;

(32) Matito, E.; Duran, M.; Solà, M. The Aromatic Fluctuation Index (FLU): A New Aromaticity Index Based on Electron Delocalization. J. Chem. Phys. 2004, 122, 014109; Erratum, íbid, 2006, 125, 059901.

(33) Fradera, X.; Poater, J.; Simon, S.; Duran, M.; Solà, M. ElectronPairing Analysis from Localization and Delocalization Indices in the Framework of the Atoms-in-Molecules Theory. Theor. Chem. Acc. 2002, 108, 214-224.

(34) Bader, R. F. W. Atoms in Molecules: A Quantum Theory; Oxford University Press: New York, 1990.

(35) Fulton, R. L.; Mixon, S. T. Comparison of Covalent Bond Indexes and Sharing Indexes. J. Phys. Chem. 1993, 97, 7530-7534.

(36) Bader, R. F. W.; Johnson, S.; Tang, T. H.; Popelier, P. L. A. The Electron Pair. J. Phys. Chem. 1996, 100, 15398-15415.

(37) Poater, J.; Fradera, X.; Duran, M.; Solà, M. The Delocalization Index as an Electronic Aromaticity Criterion: Application to a Series of Planar Polycyclic Aromatic Hydrocarbons. Chem. Eur. J. 2003, 9, 400-406.

(38) Poater, J.; Fradera, X.; Solà, M.; Duran, M.; Simon, S. On the Electron-Pair Nature of the Hydrogen Bond in the Framework of the Atoms in Molecules Theory. Chem. Phys. Lett. 2003, 369, 248-255. 
(39) Feixas, F.; Matito, E.; Poater, J.; Solà, M. Quantifying Aromaticity with Electron Delocalisation Measures. Chem. Soc. Rev. 2015, 44, 6434-6451.

(40) Poater, J.; Duran, M.; Solà, M.; Silvi, B. Theoretical Evaluation of Electron Delocalization in Aromatic Molecules by Means of Atoms in Molecules (AIM) and Electron Localization Function (ELF) Topological Approaches. Chem. Rev. 2005, 105, 3911.

(41) Krygowski, T. M.; Szatylowicz, H.; Stasyuk, O. A.; Dominikowska, J.; Palusiak, M. Aromaticity from the Viewpoint of Molecular Geometry: Application to Planar Systems. Chem. Rev. 2014, 114, 6383-6422.

(42) Chen, Z.; Wannere, C. S.; Corminboeuf, C.; Puchta, R.; Schleyer, P. V. R. Nucleus-Independent Chemical Shifts (NICS) as an Aromaticity Criterion. Chem. Rev. 2005, 105, 3842-3888.

(43) Krygowski, T. M.; Zachara-Horeglad, J. E. Resonance-Assisted Hydrogen Bonding in Terms of Substituent Effect. Tetrahedron 2009, 65, 20102014.

(44) Cruzan, J. D.; Braly, L. B.; Liu, K.; Brown, M. G.; Loeser, J. G.; Saykally, R. J. Quantifying Hydrogen Bond Cooperativity in Water: VRT Spectroscopy of the Water Tetramer. Science 1996, 271, 59-62.

(45) Pérez, C.; Zaleski, D. P.; Seifert, N. A.; Temelso, B.; Shields, G. C.; Kisiel, Z.; Pate, B. H. Hydrogen Bond Cooperativity and the Three-Dimensional Structures of Water Nonamers and Decamers. Angew. Chem. Int. Ed. 2014, 53, 14368-14372. 
Table 1. Resonance effect parameters $\left(\sigma_{R}\right)$.

\begin{tabular}{cc} 
Substituent & $\begin{array}{c}\text { Resonance effect } \\
\text { parameter (R) }\end{array}$ \\
\hline $\mathbf{N O}$ & 0.42 \\
$\mathbf{C N}$ & 0.15 \\
$\mathbf{N O}_{2}$ & 0.13 \\
$\mathbf{H}$ & 0.00 \\
$\mathbf{F}$ & -0.39 \\
$\mathbf{O H}$ & -0.70 \\
$\mathbf{N H}_{2}$ & -0.74 \\
\hline
\end{tabular}


Table 2. Relative energy with respect to $1,2,3-\mathrm{X}$ compounds $\left(\Delta \mathrm{E}\right.$ in $\left.\mathrm{kcal} \mathrm{mol}^{-1}\right), \mathrm{HB}$ distances $(\AA)$, PDI indexes of aromaticity (in electrons) calculated for the benzene ring and open-closed energy difference $\left(E_{\text {diff, }} \mathrm{kcal} \mathrm{mol}^{-1}\right)$.

\begin{tabular}{|c|c|c|c|c|c|}
\hline & Molecules & $\Delta \mathrm{E}$ & $\mathbf{R}_{\mathrm{HB}}$ & PDI & $E_{\text {diff }}$ \\
\hline & 1,2-H & 0.00 & 1.767 & 0.0815 & 11.09 \\
\hline \multirow{3}{*}{ 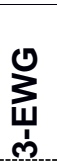 } & $1,2,3-\mathrm{NO}_{2}$ & 0.00 & 1.706 & 0.0749 & 0.57 \\
\hline & 1,2,3-NO & 0.00 & 1.740 & 0.0710 & 3.94 \\
\hline & $1,2,3-\mathrm{CN}$ & 0.00 & 1.750 & 0.0761 & 8.75 \\
\hline \multirow{3}{*}{ 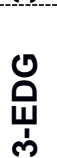 } & $1,2,3-\mathrm{NH}_{2}$ & 0.00 & 1.758 & 0.0728 & 17.02 \\
\hline & 1,2,3-F & 0.00 & 1.767 & 0.0784 & 7.90 \\
\hline & $1,2,3-\mathrm{OH}$ & 0.00 & 1.764 & 0.0756 & 6.51 \\
\hline \multirow{3}{*}{$\sum_{\substack{u \\
\dot{y}}}^{0}$} & $1,2,4-\mathrm{NO}_{2}$ & -5.37 & 1.772 & 0.0794 & 10.31 \\
\hline & 1,2,4-NO & -1.67 & 1.768 & 0.0755 & 10.56 \\
\hline & $1,2,4-C N$ & -0.22 & 1.769 & 0.0779 & 10.74 \\
\hline \multirow{3}{*}{$\begin{array}{l}\text { ㅁ } \\
\text { 岁 }\end{array}$} & $1,2,4-\mathrm{NH}_{2}$ & -3.59 & 1.740 & 0.0636 & 12.53 \\
\hline & 1,2,4-F & -4.70 & 1.751 & 0.0751 & 11.47 \\
\hline & 1,2,4-OH & -6.05 & 1.750 & 0.0697 & 11.41 \\
\hline \multirow{3}{*}{ 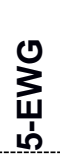 } & $1,2,5-\mathrm{NO}_{2}$ & -8.16 & 1.753 & 0.0721 & 11.13 \\
\hline & 1,2,5-NO & -5.43 & 1.741 & 0.0663 & 11.38 \\
\hline & $1,2,5-\mathrm{CN}$ & -1.73 & 1.757 & 0.0741 & 11.05 \\
\hline \multirow{3}{*}{ 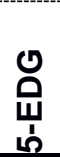 } & $1,2,5-\mathrm{NH}_{2}$ & 3.51 & 1.786 & 0.0779 & 10.87 \\
\hline & 1,2,5-F & -2.14 & 1.774 & 0.0803 & 10.97 \\
\hline & $1,2,5-\mathrm{OH}$ & -1.63 & 1.782 & 0.0802 & 11.00 \\
\hline \multirow{3}{*}{$\underbrace{0}_{\substack{\mid \\
0}}$} & $1,2,6-\mathrm{NO}_{2}$ & 0.56 & 1.624 & 0.0749 & 14.40 \\
\hline & 1,2,6-NO & 0.00 & 1.714 & 0.0723 & 12.66 \\
\hline & $1,2,6,-\mathrm{CN}$ & 0.63 & 1.732 & 0.0755 & 12.02 \\
\hline \multirow{3}{*}{ 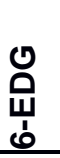 } & $1,2,6-\mathrm{NH}_{2}$ & 1.55 & 1.695 & 0.0676 & 12.12 \\
\hline & $1,2,6-\mathrm{F}$ & -2.63 & 1.733 & 0.0760 & 11.82 \\
\hline & $1,2,6-\mathrm{OH}$ & -4.01 & 1.710 & 0.0726 & 12.58 \\
\hline
\end{tabular}


Table 3. Relative energy with respect to $1,2,3-\mathrm{X}-6-\mathrm{Y}$ compounds $\left(\Delta \mathrm{E}\right.$ in $\left.\mathrm{kcal} \mathrm{mol}^{-1}\right), \mathrm{HB}$ distances $(\AA)$, PDI indexes of aromaticity (in electrons) calculated for the benzene ring and open-closed energy difference $\left(E_{\text {diff, }} \mathrm{kcal} \mathrm{mol}^{-1}\right)$.

\begin{tabular}{|c|c|c|c|c|c|}
\hline & Molecules & $\Delta \mathrm{E}$ & $\mathbf{R}_{\mathrm{HB}}$ & PDI & $E_{\text {diff }}$ \\
\hline & $1,2-\mathrm{H}$ & 0.00 & 1.767 & 0.0815 & 11.09 \\
\hline \multirow{8}{*}{ 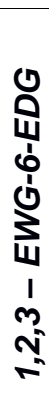 } & $1,2,3-\mathrm{NO}_{2}-6-\mathrm{NH}_{2}$ & 0.00 & 1.641 & 0.0568 & 0.45 \\
\hline & $1,2,3-\mathrm{NO}_{2}-6-\mathrm{F}$ & 0.00 & 1.676 & 0.0689 & 1.07 \\
\hline & $1,2,3-\mathrm{NO}_{2}-6-\mathrm{OH}$ & 0.00 & 1.654 & 0.0639 & 1.67 \\
\hline & $1,2,3-\mathrm{NO}-6-\mathrm{NH}_{2}$ & 0.00 & 1.674 & 0.0521 & 3.75 \\
\hline & 1,2,3-NO-6-F & 0.00 & 1.711 & 0.0650 & 4.43 \\
\hline & 1,2,3-NO-6-OH & 0.00 & 1.688 & 0.0596 & 4.89 \\
\hline & $1,2,3-\mathrm{CN}-6-\mathrm{NH}_{2}$ & 0.00 & 1.680 & 0.0600 & 9.53 \\
\hline & $1,2,3-\mathrm{CN}-6-\mathrm{F}$ & 0.00 & 1.722 & 0.0704 & 9.38 \\
\hline \multirow{10}{*}{ 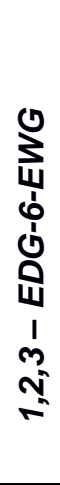 } & $1,2,3-\mathrm{CN}-6-\mathrm{OH}$ & 0.00 & 1.696 & 0.0661 & 10.14 \\
\hline & $1,2,3-\mathrm{NH}_{2}-6-\mathrm{NO}_{2}$ & -2.60 & 1.602 & 0.0600 & 21.91 \\
\hline & 1,2,3-NH$-6-\mathrm{NO}$ & -2.76 & 1.704 & 0.0571 & 19.88 \\
\hline & $1,2,3-\mathrm{NH}_{2}-6-\mathrm{CN}$ & -1.53 & 1.713 & 0.0638 & 18.61 \\
\hline & $1,2,3-\mathrm{F}-6-\mathrm{NO}_{2}$ & 2.88 & 1.625 & 0.0705 & 9.62 \\
\hline & 1,2,3-F-6-NO & 2.36 & 1.717 & 0.0680 & 9.52 \\
\hline & 1,2,3-F-6-CN & 3.17 & 1.732 & 0.0718 & 8.85 \\
\hline & $1,2,3-\mathrm{OH}-6-\mathrm{NO}_{2}$ & 4.03 & 1.617 & 0.0653 & 9.85 \\
\hline & 1,2,3-OH-6-NO & 3.56 & 1.712 & 0.0628 & 8.44 \\
\hline & 1,2,3-OH-6-CN & 4.40 & 1.723 & 0.0678 & 7.58 \\
\hline \multirow{8}{*}{ 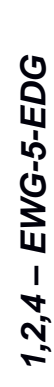 } & $1,2,4-\mathrm{NO}_{2}-5-\mathrm{NH}_{2}$ & -2.97 & 1.819 & 0.0738 & 8.91 \\
\hline & $1,2,4-\mathrm{NO}_{2}-5-\mathrm{F}$ & 2.70 & 1.787 & 0.0776 & 9.80 \\
\hline & $1,2,4-\mathrm{NO}_{2}-5-\mathrm{OH}$ & 5.38 & 1.803 & 0.0767 & 9.30 \\
\hline & $1,2,4-\mathrm{NO}-5-\mathrm{NH}_{2}$ & -0.91 & 1.818 & 0.0694 & 8.88 \\
\hline & 1,2,4-NO-5-F & 4.95 & 1.783 & 0.0740 & 10.05 \\
\hline & 1,2,4-NO-5-OH & 7.50 & 1.798 & 0.0729 & 9.57 \\
\hline & $1,2,4-\mathrm{CN}-5-\mathrm{NH}_{2}$ & 1.50 & 1.797 & 0.0745 & 10.08 \\
\hline & $1,2,4-\mathrm{CN}-5-\mathrm{F}$ & 2.40 & 1.777 & 0.0763 & 10.50 \\
\hline \multirow{10}{*}{ 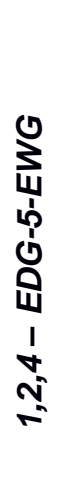 } & $1,2,4-\mathrm{CN}-5-\mathrm{OH}$ & 4.11 & 1.788 & 0.0752 & 10.23 \\
\hline & $1,2,4-\mathrm{NH}_{2}-5-\mathrm{NO}_{2}$ & -13.01 & 1.748 & 0.0535 & 11.98 \\
\hline & $1,2,4-\mathrm{NH}_{2}-5-\mathrm{NO}$ & -12.27 & 1.739 & 0.0476 & 12.13 \\
\hline & $1,2,4-\mathrm{NH}_{2}-5-\mathrm{CN}$ & -7.25 & 1.742 & 0.0568 & 12.26 \\
\hline & $1,2,4-\mathrm{F}-5-\mathrm{NO}_{2}$ & -2.56 & 1.749 & 0.0664 & 11.30 \\
\hline & 1,2,4-F-5-NO & -1.13 & 1.742 & 0.0615 & 11.56 \\
\hline & 1,2,4-F-5-CN & -1.61 & 1.749 & 0.0681 & 11.37 \\
\hline & $1,2,4-\mathrm{OH}-5-\mathrm{NO}_{2}$ & -2.27 & 1.746 & 0.0618 & 12.23 \\
\hline & 1,2,4-OH-5-NO & -0.92 & 1.739 & 0.0569 & 12.42 \\
\hline & $1,2,4-\mathrm{OH}-5-\mathrm{CN}$ & -2.19 & 1.743 & 0.0633 & 12.34 \\
\hline
\end{tabular}

